\title{
The Need of Collaboration in Medical Education for Worldwide Disaster
}

\author{
Nobuyasu Komasawa, MD, PhD; Fumio Terasaki, MD, PhD; Masao Tomioka, MD, PhD; \\ Ryuichi Saura, MD, PhD; Ryo Kawata, MD, PhD
}

Key Words: disaster medical education, worldwide, collaboration

$\mathrm{N}$ atural disasters respect no geographic border. While several international collaboration systems for the disaster management are effective, only a few international medical education programs currently exist. ${ }^{1,2}$

The reason why such programs rarely exist may be attributed to the regional characteristics of disasters. Japan located on the eastern edge of Asia experiences many types of disasters. For example, large earthquakes have killed thousands within the span of several decades. Thousands peoples have died in urban areas at the Hanshin-Awaji great earthquake in 1995. Earthquakes can also cause catastrophic tsunamis, such as those following the Great East Japan earthquake in 2011, which led to a nuclear meltdown at the Fukushima nuclear power plant. In addition to the earthquakes, Japan also experiences typhoons, which cause major water damage. In recent years, typhoons have increased in strength and caused a catastrophic damage. The United States also experiences earthquakes or hurricanes for which they use different systems of prevention or management.

In this era of global climate change, countries all around the world may encounter a new type of disaster for which they lack prior experience. ${ }^{3}$ Valuable experience and knowledge with disaster management learned from these disasters should be applied toward the future prevention and management, not only in the disaster region itself, but also worldwide. Medical education pertaining to worldwide disaster prevention and management is essential. Now is the time to integrate disaster management to medical education. Given the importance of medical staff collaborations in disaster management, an interprofessional education approach is also warranted. ${ }^{4}$
While direct on-site education may be difficult and impractical, simulation-based education may be an effective approach, as it would entail studying disasters from many different regions and train the medical staffs to develop nontechnical skills to help with disaster management. In particular, augmented or virtual reality may be useful tools that enhance the disaster medical education experience for medical professionals. ${ }^{5}$

Now, it is a perfect time to integrate and promote international medical education collaboration for disaster management and prevention.

\section{About the Authors}

Medical Education Center, Osaka Medical College, Osaka, Japan (Drs Komasawa, Terasaki, Kawata) and Department of Rehabilitation, Osaka Medical College, Osaka, Japan (Drs Tomioka, Saura).

Correspondence to Nobuyasu Komasawa, M.D., Ph.D., Medical Education Center, Osaka Medical College, Daigaku-machi 2-7, Takatsuki, Osaka 569-8686, Japan. (e-mail: ane078@osaka-med.ac.jp).

\section{REFERENCES}

1. Shinchi K, Matsunaga H, Fukuyama Y. Proposal of a model of disaster medical education for practical risk management and disaster nursing: the SINCHI education model. Prehosp Disaster Med. 2019;34:438-441.

2. Della CF, Hubloue I, Ripoll GA, et al. The European Masters Degree in Disaster Medicine (EMDM): a decade of exposure. Front Public Health. 2014;2:49.

3. Kako M, Ranse J, Yamamoto A, et al. What was the role of nurses during the 2011 great East earthquake of Japan? An integrative review of the Japanese literature. Prehosp Disaster Med. 2014;29:275-279.

4. Komasawa N, Berg BW. Interprofessional simulation training for perioperative management team development and patient safety. J Perioper Pract. 2016;26:250-253.

5. Farra S, Hodgson E, Miller ET, et al. Effects of virtual reality simulation on worker emergency evacuation of neonates. Disaster Med Public Health Prep. 2019;13:301-308. 